\title{
Spirometric Abnormalities in Patients with Type 2 Diabetes Mellitus
}

\author{
Santosh Kumar Nemagouda ${ }^{1}$ \\ ${ }^{1}$ Associate Professor, Department of Pulmonology, Sri B. M. Patil Medical College, BLDE University, \\ Vijayapur, Karnataka, India.
}

\section{ABSTRACT}

\section{BACKGROUND}

We wanted to document abnormalities on spirometry in patients with type 2 diabetes mellitus (DM) and study the determinants of these.

\section{METHODS}

This is a hospital based cross sectional study. Fifty-two type 2 DM patients attending the diabetic clinic of Shri B. M. Patil Medical College Vijayapur, Karnataka, were included in this study and they underwent spirometry after giving consent for the study. The absolute FEV1 and FVC were compared with the predicted ones and expressed as a percentage of the predicted values. Additional information collected were, gender, age, weight, height and the latest glycated haemoglobin. Data was presented as mean \pm SD. $\chi 2$ test was used to study differences in proportions and Pearson's coefficient was calculated for correlations.

\section{RESULTS}

52 patients with type 2 DM were recruited in this study between November 2015July 2017. Thirty were males (58\%) and twenty-two (42\%) were females. Forty-five patients (86\%) had restrictive abnormality on PFT in our study. In seven patients, PFT reports were normal. The mean FEV1, FVC \& FEV1/FVC were 75\% pred, 70\% pred and 117 respectively. Out of 52 patients only 7 patients were having normal PFT study while remaining 45 patients were restrictive form of abnormality on PFT which was statistically significant $(\mathrm{p}<0.05)$.

\section{CONCLUSIONS}

Spirometric abnormalities are common in Type $2 \mathrm{DM}$ and is a significant determinant of the same.

\section{KEY WORDS}

Diabetes Mellitus, Respiratory Function Tests, Spirometry
Corresponding Author:

Dr. Santosh Kumar Nemagouda,

S/o. R. S. Nemagouda, Sri Siddeshwar Housing Colony, \#85, North, Athani Road,

Vijyapur, Karnataka, India.

E-mail: pulmonologist20007@yahoo.co.in

DOI: $10.14260 /$ jemds/2019/655

Financial or Other Competing Interests: None.

How to Cite This Article: Nemagouda SK. Spirometric abnormalities in patients with type 2 diabetes mellitus. J. Evolution Med. Dent. Sci. 2019;8(40): 3014-3018, DOI:

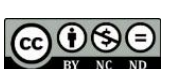




\section{BACKGROUND}

Diabetes mellitus is a modern-day disease. It is increasing in incidence, prevalence and complications associated with it.[1] Chronic hyperglycaemia is responsible for the damage, dysfunction, and failure of various organs, like the eyes, kidneys, nerves, heart, lungs and blood vessels. The diabetes mellitus is a life-long disease, involving multiple systems of the body with devastating complications, which end up in severe disability and death.[2] The damage, dysfunction and their complications of various organs are mainly a consequence of macro-vascular and micro-vascular damage.[3] The mechanism of pulmonary damage \& dysfunction in chronic hyperglycaemia is uncertain, though it has been suggested that the chronic hyperglycaemic is responsible for the chronic pulmonary inflammation, resulting in air way damage.[4,5] The decreased levels of antioxidant and increased susceptibility of lungs to oxidative stress results in the subsequent loss of lung function. ${ }^{[6]}$ The studies have demonstrated that the thickening of, the walls of alveoli, alveolar capillaries and pulmonary arterioles are responsible for pulmonary dysfunction and it's complications in diabetes mellitus. ${ }^{[7,8]}$ The chronic hyperglycaemia damages the connective tissues elements like collagen and elastin which is associated with the pulmonary damage and dysfunction.[9] The patients with diabetes mellitus have impaired immune system, because of this there is impairment in pulmonary function.[10] The clinical symptoms in diabetic patients are shortness of breath, dyspnoea, wheezing and easy fatigability make clinicians more alert to coronary artery disease (CAD) than respiratory illness. The lungs are also a target organs in diabetic patients, and such clinical features might be due to pulmonary dysfunction and complications rather than CAD alone, and prompt evaluation of cardiorespiratory system is must in diabetic patients.[11] The advancement in technology have made the spirometry more accurate, reliable and easy to use in daily clinical practice. Spirometry is a basic pulmonary function test (PFT) which assesses the lung volumes and flows, helps in detecting obstructive and restrictive impairment in lung function. ${ }^{[12]}$ It is now regarded as an integral component of any respiratory medical surveillance program. ${ }^{[13]}$ The utility of spirometry in diabetes mellitus patients, was highlighted when the inhaled insulin therapy option was introduced for treatment of diabetes mellitus.[14,15] Hence the present study "The spirometric abnormalities in patients with type 2 diabetes mellitus".

\section{METHODS}

Patients attending diabetic clinic of a tertiary care teaching hospital during November 2015 to July 2017 were included in this study after informed consent. 52 patients were consented for this study. All the patients were diabetic according to American Diabetes Association (ADA) criteria. [16] The following information was collected about each patient: gender, date of birth duration of diabetes weight in kilograms, height in centimetres latest glycated haemoglobin. Glycated haemoglobin. A chest Roentgenogram in posterior anterior (PA) view was performed in all the patients.
The patients then underwent spirometry on the Spirotech PFT System (Clarity India.) in accordance with the American Thoracic Society standards as described previously.[17,18] The following parameters were recorded: Forced Vital Capacity (FVC) in litres, Forced Expiratory Volume in 1st second (FEV1) in litres and the ratio of FEV1 to FVC (FEV1/FVC).The best of three such forced expiratory records were taken for the study.

The absolute FEV1 and FVC were compared with the FEV1 and FVC predicted based on height, age and gender and thereby expressed as a percentage of predicted. A restrictive ventilatory disturbance was diagnosed when the FVC was less than $80 \%$ of the predicted ratio but the FEV1/FVC ratio was greater than 0.7 . An obstructive ventilatory disturbance was diagnosed when the FEV1 was low (i.e. $<80 \%$ of the predicted) in the presence of a normal FVC $(>80 \%$ of the predicted) or when the FEV1/FVC ratio was $<0.7$.

\section{Statistical Analysis}

Data were presented as mean \pm SD. $\chi 2$ test was used to study differences in proportions and Pearson's coefficient was calculated for correlations. Statistical analysis was performed on SPSS version 13.

\section{RESULTS}

52 patients with type 2 DM were recruited in this study between November 2015 to July 2017. Out of 52, males $30(58 \%)$ and $22(42 \%)$ females. The mean BMI was $23 \pm 2.4$ $\mathrm{kg} / \mathrm{m}^{2}$ and HbA1c was 8.8. The mean duration of diabetes was approximately 12 years. The Chest Roentgenogram was normal in all the patients. The mean FEV1, FVC \& FEV1/FVC were $75 \%$ pred, $70 \%$ pred and 117 respectively. The FEV1, FVC \& FEV1/FVC were compared between males and females, which is statistically insignificant but had statistically significant difference with respect to BMI \& HbA1c $(p<0.05)$.Out of 52 patients only 7 patients were having normal PFT study while remaining 45 patients were having restrictive form of abnormality on PFT which was statistically significant ( $\mathrm{p}<0.05)$. Out of 45 patients, 27 were having mild, 13 were having moderate and 5 were having sever restrictive pattern of PFT. The severity of restriction correlated to the duration \& poor glycaemic control, of type 2 diabetes mellitus.

\begin{tabular}{|c|c|}
\hline Age (Mean) & $\mathbf{6 2 . 8 0}$ Years \\
\hline Male/Female & $30 / 22$ \\
\hline Duration of DM2 (mean) \pm SD & $11.94 \pm 1.41$ \\
\hline HbA1c (mean) \pm SD & $8.80 \pm 1.70$ \\
\hline BMI (mean) \pm SD & $23.14 \pm 2.0$ \\
\hline FVC\% Pred (mean) \pm SD & $64 \pm 4.24$ \\
\hline FEV1\% Pred (mean) \pm SD & $75.03 \pm 4.95$ \\
\hline FEV1/FVC (mean) \pm SD & $117.05 \pm 14.85$ \\
\hline \multicolumn{2}{|c|}{ Table 1. Variables } \\
\hline
\end{tabular}

\begin{tabular}{|c|c|c|}
\hline Variables & Male & Female \\
\hline Age (mean) \pm SD & $62 \pm 12.73$ & $63 \pm 4.95(\mathrm{p}=0.73)$ \\
\hline Duration of DM2 (mean) \pm SD & $12.5 \pm 1.41$ & $11.2 \pm 2.83(\mathrm{p}=0.03)$ \\
\hline HbA1c (mean) \pm SD & $7.3 \pm 0.99$ & $11.8 \pm 1.70(\mathrm{p}<0.0001)$ \\
\hline BMI (mean) \pm SD & $21.6 \pm 6.96$ & $25.3 \pm 8.92(\mathrm{p}=0.09)$ \\
\hline FVC\% Pred (mean) \pm SD & $64 \pm 4.24$ & $64 \pm 6.36(\mathrm{p}=1.00)$ \\
\hline FEV1 \% Pred (mean) \pm SD & $72 \pm 2.83$ & $80 \pm 12.73(\mathrm{p}=0.0016)$ \\
\hline FEV1/FVC (mean) \pm SD & $113 \pm 11$ & $123 \pm 17.68(\mathrm{p}=0.0154)$ \\
\hline \multicolumn{2}{|r}{ Table 2. Male Female Comparison } \\
\hline
\end{tabular}




\begin{tabular}{|c|c|}
\hline Normal & $7(13.46 \%)$ \\
\hline Abnormal & $45(86.54 \%)$ \\
\hline \multicolumn{2}{|c|}{ Table 3. PFT Reports } \\
\hline Mild restriction (FVC 60-80\% of the predicted) & $27(60 \%)$ \\
\hline Moderate restriction (FVC 40-59\% of the predicted) & $13(28.89 \%)$ \\
\hline Sever restriction (FVC <40\% of the predicted) & $05(11.11 \%)$ \\
\hline \multicolumn{2}{|c|}{ Table 4. Abnormal PFT Reports } \\
\hline
\end{tabular}

\begin{tabular}{|c|c|c|c|}
\hline $\begin{array}{c}\text { Variables } \\
\text { (Mean) } \pm \text { SD }\end{array}$ & $\begin{array}{c}\text { Mild } \\
\mathbf{2 7}(\mathbf{6 0 \%})\end{array}$ & $\begin{array}{c}\text { Moderate } \\
\mathbf{1 3}(\mathbf{2 8 . 8 9 \% )}\end{array}$ & $\begin{array}{c}\text { Severe } \\
\mathbf{0 5}(\mathbf{1 1 . 1 1} \%)\end{array}$ \\
\hline Age & $62 \pm 5.66$ & $63 \pm 4.74$ & $70 \pm 9.19$ \\
\hline BMI & $24 \pm 2.01$ & $22 \pm 1.45$ & $20 \pm 5.52$ \\
\hline Duration of DM2 & $10 \pm 2.83$ & $12 \pm 3.54$ & $20 \pm 3.14$ \\
\hline HbA1c & $12 \pm 1.70$ & $12 \pm 1.48$ & $7.5 \pm 1.13$ \\
\hline FVC\% Pred & $65 \pm 4.24$ & $51 \pm 4.24$ & $31 \pm 0.70$ \\
\hline FEV1\% Pred & $76 \pm 4.95$ & $61 \pm 12.73$ & $37 \pm 6.36$ \\
\hline FEV1/FVC & $115 \pm 14.84$ & $119 \pm 33.94$ & $121 \pm 14.85$ \\
\hline \multicolumn{4}{|c|}{ Table 5. Restrictive PFT Reports } \\
\hline
\end{tabular}

\section{DISCUSSION}

In our study it was showed the majority of patients with type 2 diabetes were having abnormal PFT. The FEV1, FVC \& FEV1/FVC were compared between males and females, which is statistically insignificant but had statistically significant difference with respect to BMI \& HbA1c ( $p<0.05)$. Out of 52 patients only 7 patients were having normal PFT reports while remaining 45 patients were having restrictive form of abnormality on PFT which was statistically significant ( $p$ $<0.05$ ). Out of 45 patients, 27 were having mild, 13 were having moderate and 5 were having severe restrictive pattern of PFT. The severity of restriction correlated to the duration \& poor glycaemic control, of type 2 diabetes mellitus.

Meo. S.A. et al., conducted the similar study in Asian population in Saudi Arabia and had reported the similar findings when compared with control. The effect of BMI in reducing lung function has been well documented by Li AM. The effect of BMI in reducing lung function may be due to reduced chest wall compliance and increased airway resistance.[19] The Agarwal et al revealed that pulmonary function is indeed impaired in patients of DM as compared to controls. ${ }^{[20]}$

Tangadhuri. et al., study showed lung the pulmonary functions FVC, FEV1, PEF and FEF 25\%-75\% are decreased in Type- 2 diabetes mellitus compared to controls.[21] Karale et al.[22] decreased FVC as the duration of diabetes increased. FVC at 5-6 years of duration is $3.60 \pm 0.45$, at $6-10$ years of duration is $3.20 \pm 0.48$ and $>10$ years duration is $2.97 \pm 0.29$. There was a decrease in FVC as the duration of diabetes increased with a $\mathrm{P}$ value $=0.002$ which is highly significant. Which was similar to our study. Karale et al. \& our study is in agreement with Wendy DA et al who studied the glycaemic exposure is associated with reduced pulmonary function in type- 2 diabetes found a decrease in FVC at an annual rate of $68 \mathrm{ml} /$ year.[23]

Gregory L. Kinney et al. have observed a moderate reduction in FVC, FEV1 and diffusing capacity for carbon monoxide of the lung in patients with type 1 and type 2 diabetes [24] Similarly, Mori $\mathrm{H}$ et al. have found that increased duration of diabetes is associated with proportionate loss of $\%$ DLCO. They also suggested that pulmonary function tests such as \%VC, FEV1 and $\mathrm{PaCO}_{2}$ had no significant association with duration of diabetes. [25]
The Copenhagen City Heart Study done over 15 years showed that there was consistently lower (FEV1) and (FVC) in diabetics compared to normal individuals.[26]

Muhammad Irfan et al., studied PFT in diabetics and showed that there was a significant reduction in forced vital capacity (FVC), FEV1 and slow vital capacity. They also studied that impaired lung function was independent of smoking and is likely to be a complication of diabetes itself.[27] David A. Kaminsky have opined that lung function is an important marker of increased risk of mortality in diabetic patients. Further, it is suggested that low FEV1 is a marker of diabetes or poor glycaemic control, it is better to add the spirometer to the equipment available for monitoring the control of diabetes and its important complications. [28]

Wendy A. Davis et al. showed that reduced lung volumes are the result of chronic complications of DM and is related to glycaemic exposure. They also revealed that airflow limitation is a predictor of mortality.[24]

Bruce B. Duncan et al. have found in their study that an increase in levels of interleukin-6 signifying a low-grade inflammation may predict an impending onset of type 2 diabetes.[29] Connie C.W. Hsia have stated that moderate lung restriction is seen in type 2 diabetes as in type 1 diabetes. FVC and FEV1 are proportionately reduced as the increase in glycaemic levels and loss of lung diffusing capacity (DLCO).[26]

The all currently available data supports the association between diabetes mellitus and impairment in lung function but the exact pathophysiological mechanism responsible for this association is uncertain. The studies have demonstrated that the impairment in lung function in diabetes is due to the chronic inflammation, increases oxidative stress, impaired immunity and recurrent chest infections. The Cross-sectional studies have suggested that there is $3-10 \%$ lower lung volumes in patients with diabetes mellitus than non-diabetic adults, independent of BMI and smoking status.[30]

If the association between the microangiopathy in diabetes mellitus and pulmonary dysfunction is clearly established \& explained, the inconsistency regarding lung function decline in the longitudinal analyses can be attributed to the lack of stratification of participants with diabetes by the presence or absence of microangiopathy. Chance et al.[31] have showed that the lung function measurements correlated with extra-pulmonary microangiopathy. There is rise in incidence rate of Diabetes, Obesity, Heart failure which in turn negatively impact lung function at population level. If patients with diabetes exhibit subclinical pulmonary dysfunction, in the context of hypoxia associated with acute or chronic lung conditions such as Pneumonia \& COPD or hypoxia associated with fluid overload secondary to heart failure, the loss of pulmonary reserve may become clinically important.[32]

The thorough understanding of pulmonary dysfunction in patients with diabetes is needed and is must, in the context of pursuing insulin delivery via inhalation route to treat diabetes mellitus.[33-36] Pre-existing lung dysfunction may interfere with the inhaled drug absorption and bioavailability. The chronically inhaled insulin can cause lung toxicity and worsen the already reduced lung function by its pro-inflammatory and potential immunogenic properties.[33-36] The complete and thorough understanding pulmonary function in patients with diabetes mellitus may 
improve patient selection and guide insulin delivery via inhalers.

\section{CONCLUSIONS}

Spirometric abnormalities are common in type $2 \mathrm{DM}$ and are significant determinants of the same.

\section{REFERENCES}

[1] Meo SA. Diabetes mellitus: health and wealth threat. Int ] Diab Mellitus 2009;1(1):42.

[2] James RG, Alberti KGMM, Mayer BD, et al. Report on the expert committee on the diagnosis and classification of diabetes mellitus. Diab Care 2002;25:S5-S20.

[3] Arnalich F, Hernanz A, Lopez-Maderuelo D. Enhanced acute-phase response and oxidative stress in older adults with type II diabetes. Horm Metab Res 2000;32(10):407-12.

[4] Walter R, Beiser A, Givelber RJ, et al. The association between glycemic state and lung function: the Framingham heart study. Am J Respir Crit Care Med 2003;167(6):911-6.

[5] Cirillo DJ, Agrawal Y, Cassano PA. Lipids and pulmonary function in the third national health and nutrition examination survey. Am J Epidemiol 2002;155(9):842-8.

[6] Brownlee M. Biochemistry and molecular cell biology of diabetic complications. Nature 2001;414(6865):813-20.

[7] Sandler M, Bunn AE, Stewart RI. Pulmonary function in young insulin-dependent. Chest 1986;90(5):670-5.

[8] Matsubara T, Hara F. The pulmonary function and histopathological studies of the lung in diabetes mellitus. Nippon Ika Daigaku Zasshi 1991;58(5):528-36.

[9] Ljubic' S, Metelko Z, Car N, et al. Reduction of diffusion capacity for carbon monoxide in diabetic patients. Chest 1998;114(4):1033-5.

[10] Weynand B, Jonckheere A, Frans A, et al. Diabetes mellitus induces a thickening of the pulmonary basal lamina. Respiration 1999;66(1):14-9.

[11] Gildea TR. Pulmonary function testing, 2009. http://www.clevelandclinicmeded.com/medicalpubs/di seasemanagement/pulmonary/pulmonary-functiontesting/\#cesec36, cited date; Oct, 2009.

[12] Ruppel GL. Pulmonary function testing - trends and techniques. Respir Care Clinics North America 1997;3:155-81.

[13] McKay, Ray T, Edward H. Pulmonary function testing in industry. In: Zenz CO, Bruca D, Edward HP, eds. Occupational medicine. London: Mosby 1984: p. 229.

[14] Meo SA, Al-Drees AM, Arif M, et al. Lung function in type 2 Saudi diabetic patients. Saudi Med J 2006;27(3):33843.

[15] Meo SA. In: Sixth international conference in diabetes science and technology, Atlanta, USA: 2006.

[16] Report of the Expert Committee on the diagnosis and classification of diabetes mellitus. Diabetes Care 1997;20(7):1183-97.
[17] Mohan A, Premanand R, Reddy LN, et al. Clinical presentation and predictors of outcome in patients with severe acute exacerbation of chronic obstructive pulmonary disease requiring admission to intensive care unit. BMC Pulm Med 2006;6:27.

[18] American Thoracic Society: Standards for the diagnosis and care of patients with chronic obstructive pulmonary disease. Am J Respir Crit Care Med 1995;152(5 Pt 2):S77 -S121.

[19] Li AM, Chan D, Wong E, et al. The effect of obesity on pulmonary function. Arch Dis Child 2003;88(4):361-3.

[20] Kaur S, Agarwal N. Pulmonary function tests in type 2 diabetes mellitus. Arch Med Health Sci 2016;4(1):35-9.

[21] Thangadhurai A. Assessment of pulmonary function tests in type 2 Dm. IOSR Journal of Dental and Medical Sciences 2018;17(8):23-6.

[22] Karale M, Karale B, Usendi C, et al. Evaluation of pulmonary functions in patients of type-2 diabetes mellitus. Int J Adv Med 2016;3(4):1020-3.

[23] Davis WA, Knuiman M, Kendell P, et al. Glycemic exposure is associated with reduced pulmonary function in type-2 diabetes: the Fremantle Diabetes Study. Diabetes Care 2004;27(3):752-7.

[24] Kinney GL, Black-Shinn JL, Wan ES, et al. Pulmonary function reduction in diabetes with and without chronic obstructive pulmonary disease. Diabetes Care 2014;37(2):389-95.

[25] Mori H, Okubo M, Okamura M, et al. Abnormalities of pulmonary function in patients with non-insulindependent diabetes mellitus. Intern Med 1992;31(2):189-93.

[26] Lange P, Parner J, Schnohr P, et al. Copenhagen City Heart Study: longitudinal analysis of ventilatory capacity in diabetic and non-diabetic adults. Eur Respir J 2002;20(6):1406-12.

[27] Irfan M, Jabbar A, Haque AS, et al. Pulmonary functions in patients with diabetes mellitus. Lung India 2011;28(2):89-92.

[28] Kaminsky DA. Spirometry and Diabetes: implications of reduced lung function. Diabetes Care 2004;27(3):837-8.

[29] Yeh HC, Punjabi NM, Wang N, et al. Vital capacity as a predictor of incident type 2 diabetes the atherosclerosis risk in communities study. Diabetes Care 2005;28(6):1472-9.

[30] Klein OL, Krishnan JA, Glick S. et al. Systematic review of the association between lung function and Type 2 diabetes mellitus. Diabetic Medicine 2010;27(9):977-87.

[31] Chance WW, Rhee C, Yilmaz C, et al. Diminished alveolar microvascular reserves in type 2 diabetes reflect systemic microangiopathy. Diabetes Care 2008;31(8):1596-601.

[32] Hsia CC, Raskin P. Lung function changes related to diabetes mellitus. Diabetes Technol Ther 2007;(9 Suppl 1):S73-S82.

[33] Cefalu WT, Skyler JS, Kourides IA, et al. Inhaled human insulin treatment in patients with type 2 diabetes mellitus. Ann Intern Med 2001;134(3):203-7.

[34] Weiss SR, Cheng SL, Kourides IA, et al. Inhaled insulin provides improved glycemic control in patients with type 2 diabetes mellitus inadequately controlled with oral agents: a randomized controlled trial. Arch Intern Med 2003;163(19):2277-82. 
[35] Laube BL. Treating diabetes with aerosolized insulin. Chest 2001;120(Suppl 3):99S-106S.
[36] Hsia CC, Raskin P. The diabetic lung: relevance of alveolar microangiopathy for the use of inhaled insulin. Am J Med 2005;118(3):205-12. 